\title{
Inflation and Inflation Uncertainty in the United Kingdom Evidence from GARCH modelling
}

\author{
A. Kontonikas ${ }^{\text {a }}$ \\ ${ }^{a}$ Department of Economics and Finance, Brunel University, Uxbridge, UK
}

\begin{abstract}
This paper examines the relationship between inflation-uncertainty and the impact of inflation targeting using British data over the period 1972-2002. Uncertainty is proxied using the estimated conditional volatility from symmetric, asymmetric, and component GARCH-M models of inflation. The results indicate a positive relationship between past inflation and current uncertainty. We control for the indirect effect of lower average inflation throughout the last decade of inflation targeting and find that the adoption of an explicit target eliminates inflation persistence and reduces long-run uncertainty. Monetary authorities of implicit targeting countries should consider the extra benefits associated with formal targets.
\end{abstract}

JEL classifications: E31; E52; C22

Keywords: Inflation, Inflation Targeting, Inflation Uncertainty, GARCH models

* Corresponding author. Tel.: +44-1895-274000-ext. 3853; fax: +44-1895-203384.

E-mail address: alexandros.kontonikas@brunel.ac.uk 


\section{Introduction}

In the 1990's a number of countries adopted explicit inflation targeting (IT) monetary policy frameworks. Over the same period, their inflation rates became lower and less variable. The reduction in inflation and inflation variance seems to be more generalised since it is observed both in countries where formal targets are in use and in non-targeting countries. Cecchetti and Ehrmann (2000) argue that over the last decade, aversion to inflation variability increased in all major economies irrespective of whether they were operating under IT or not. Higher non-forecastable inflation variability increases inflationary uncertainty and induces significant economic costs by distorting the intertemporal and intratemporal allocation decisions of individuals and firms, by re-distributing wealth between debtors and creditors, and by reducing the effectiveness of relative prices in co-ordinating economic actions.

Friedman (1977) suggests a positive correlation between the level of inflation and inflation uncertainty, with higher inflation leading to greater uncertainty and lower output growth. Ball (1992) formalises Friedman's argument in the context of an asymmetric information game between the public and the policy maker. The empirical relationship between average inflation and inflation uncertainty has been studied extensively throughout the last three decades, with the results largely accepting the Friedman-Ball prediction. Thus, policies that lower average inflation lead to lower inflation uncertainty with apparent economic benefits. A key question that arises is whether explicit IT leads to a greater decrease in inflation uncertainty, as compared to the case where formal targets are not announced. Targets have an independent role if they help to anchor inflation expectations and to produce an additional decline in inflation uncertainty. Johnson (2002) finds that formal targets reduce expected inflation but bring no additional benefits in the form of lower uncertainty.

In this paper we take a closer look at the effect of IT on average inflation and inflation uncertainty using British data over the period 1972-2002. The United Kingdom (UK) was among the first major economies to adopt explicit targeting in October 1992. We employ a variety of GARCH related models to account for timevarying inflation volatility. GARCH techniques are popular in empirical investigations of the inflation-uncertainty relationship, since the estimated conditional volatility can serve as a proxy for uncertainty. Furthermore, GARCH-inmean (GARCH-M) specifications augmented by lagged inflation allow for the 
possibility of a simultaneous feedback relationship between inflation and uncertainty. In addition, given the importance of long-run price stability, we use Component GARCH models to decompose inflation uncertainty into a temporary a permanent component and examine whether past inflation and IT affect long-run uncertainty. The results have important implications for the design of monetary policy given the decade-long targeting experience. This study's major contribution to the existing literature is the finding that, even if we take into account the indirect effect of lower average inflation, the adoption of formal targeting exerts a direct negative impact on long-run uncertainty, thereby promoting macroeconomic stability.

The rest of the paper is organised as follows. The next section discusses the theoretical background and empirical evidence concerning the inflation-uncertainty relationship. Section 3 presents an overview the data. Sections 4.1 to 4.5 contain the empirical models of inflation and uncertainty. Section 5 provides conclusions and policy implications.

\section{Sources and measures of inflation uncertainty}

The idea that a rise in the level of inflation raises uncertainty about future inflation is central in Friedman's (1977) Nobel address. In the model by Ball (1992) there are two types of policymakers who stochastically alternate in power, and the public knows that only one type (tough) is willing to bear the economic costs of disinflation. When inflation is low both types of policymakers will try to keep it so, thus uncertainty concerning future inflation will also be low. On the other hand, when inflation is high uncertainty about the future monetary stance and the future path of inflation will be greater, since the public doesn't know how long it will be before a tough type comes along and disinflates.

Reversing the 'causation' link of the Friedman-Ball view, Cukierman and Meltzer (1986) and Cukierman (1992) show that higher inflation uncertainty will raise the optimal inflation rate. Both studies build upon the traditional Barro-Gordon framework: the policymaker maximises his own (politically motivated) objective function that is positively related to economic stimulation through monetary surprises and negatively related to monetary growth. The relative weights assigned to each target evolve stochastically over time. The money supply process is also random, due to imprecise monetary control procedures. Thus, the public faces an inference problem when trying to distinguish between persistent changes in the objectives and transitory monetary control errors. An increase in uncertainty about 
money growth and inflation provides the policymaker with an incentive to create an inflation surprise to stimulate real activity leading to a positive correlation between uncertainty and optimal average inflation.

In empirical investigations of the inflation-uncertainty relationship, a measure for uncertainty needs to be employed Early studies use unconditional volatility measures; for instance Fischer (1981) employs the moving standard deviation of inflation. Such measures have a drawback in the sense that higher variability need not necessarily imply higher uncertainty. This will be the case, only if agents don't possess the relevant information to predict part of the increased variability. In survey-based studies, expected inflation and uncertainty are approximated using inflation forecasts of individual respondents. Johnson (2002) measures uncertainty as the standard deviation of individual forecasts within a calendar year, and as the average next-year forecast error and finds a strong positive link between past inflation and current uncertainty in line with the Friedman-Ball view.

Finally, ever since Engle's (1982) seminal paper on ARCH and the subsequent GARCH extension by Bollerslev (1986), inflation uncertainty is often proxied by the estimated one-step ahead conditional variance from GARCH models of inflation. Contrary to other time-series measures of uncertainty, GARCH specifications allow the researcher to formally test for constant uncertainty over the sample period. Using GARCH estimates of uncertainty, previous UK evidence is supportive for the Friedman-Ball link ${ }^{1}$.

In these studies however, the empirical investigations end by the mid-1990's not covering the crucial decade of IT. In addition, they don't distinguish between short-run / long-run inflation uncertainty. The effect of uncertainty on economic decision-making is not the same in the short-run as in the long-run. Short-run uncertainty is most likely to affect temporal decisions, while uncertainty about the long-run inflation affects more seriously the intertemporal decision making. Most of the uncertainty costs, such as added risk in long-term contracts, are due to long-run uncertainty. Ball and Cecchetti (1990) decompose US inflation into a permanent (random walk) component and a transitory component. They find a much stronger relationship between the level of inflation and the variance of permanent shocks and interpret it as evidence that higher inflation increases long-run uncertainty.

\footnotetext{
${ }^{1}$ See among others, Joyce (1995), Baillie et al (1996), Grier and Perry (1998).
} 


\section{An overview of UK inflation data}

Inflation is measured as the first difference of the seasonally adjusted log consumer price index $(\mathrm{CPI}), \pi_{t}=100 *\left(\ln C P I_{t}-\ln C P I_{t-1}\right)$, using monthly and quarterly data in order to examine the relationship between inflation- uncertainty and IT over alternative time horizons ${ }^{2}$. UK monetary policy has undergone important changes throughout the period under investigation. In October 1992, following a 2year ERM membership the UK government adopted IT. By May 1997, the UK Central Bank was awarded operational independence in setting short-term interest rates to meet the government's stated target-currently $2.5 \%$. This study utilises 370 monthly and 122 quarterly UK observations over the period 1972-2002. A decade of targeting experience is covered allowing us to study the effects of IT on inflation dynamics and uncertainty over a long horizon. The data are obtained from OECD's Main Economic Indicators: Historical Statistics series.

Figure 1 plots the year-to-year mean and standard deviation of annual inflation. It appears that periods of higher average inflation correspond to periods of more volatile inflation. During the 10 years of targeting regime, both the level of inflation and its unconditional volatility have been strikingly lower.

[Figure 1 about here]

\subsection{Unit Root tests}

Previous evidence considering the stationarity of UK inflation rate provides mixed results. For instance, Grier and Perry (1998) show that CPI inflation over the post WWII period (1948:10-1993:12) is non-stationary. Joyce (1995) uses quarterly data and contends that over the same period, inflation is stationary, but over a shorter sub-period (1976-1994), the Augmented Dickey Fuller (ADF) test cannot reject the unit root-null hypothesis. Table 1 reports the results from ADF and Phillips-Perron (PP) unit root tests with an intercept and a deterministic linear trend. Following Fountas et al (2000), a sensitivity test is performed for the order of augmentation (d) by estimating the ADF regressions with a small and a large number of lagged difference terms. In addition, Table 1 presents the ADF $t$-statistic for orders of augmentation chosen by the reduction and the Schwartz information criteria (see Table 1 notes for more details). PP tests are also estimated for alternative Bartlett kernel truncation lags. Overall, the results suggest that UK CPI inflation over the

\footnotetext{
${ }^{2}$ Quarterly and even lower frequency data are more appropriate from the point of view of the monetary authority, due to the long lags in the implementation of monetary policy. Monthly sampling provides a robustness check for the quarterly results.
} 
period 1972-2002 can be treated as integrated of order zero, I(0), variable. Thus, the methods suggested by Ball and Cecchetti (1990) and Evans (1991) to decompose inflation uncertainty into long-run and short-run components, based upon the assumption of unit root in the level of inflation, are not applicable to our sample. Since the stationarity criterion is satisfied, we proceed by estimating models from the autoregressive family to accommodate for the significant inertia inherent in inflation.

[Table 1 about here]

\section{Empirical models and results}

\subsection{Benchmark autoregressive conditional mean model}

The first step in time varying volatility modelling is to specify a sufficient equation for the conditional mean of the series under investigation. Given the absence of a commonly accepted structural model for inflation, autoregressive specifications are popular in the empirical literature and are employed by Grier and Perry (1998), and Joyce (1995) among others to analyse the UK experience. Based on the Akaike - Schwartz information criteria and the whiteness of the residuals, general-to-specific approach led to the following models:

Monthly (M) $\quad \pi_{t}=\gamma_{0}+\gamma_{1} \pi_{t-1}+\gamma_{2} \pi_{t-3}+\gamma_{3} \pi_{t-6}+\gamma_{4} \pi_{t-12}+u_{1 t}$

Quarterly $(Q) \quad \pi_{t}=\gamma_{0}+\gamma_{1} \pi_{t-1}+\gamma_{2} \pi_{t-4}+u_{2 t}$

Allowing for maximum lag-length of one year, or more, is usual practise in time series studies of inflation in an effort to model the persistence of the data (see e.g. Bollerslev, 1986). Table 2 summarizes the ordinary least squares parameter estimates (robust estimates) and diagnostic statistics of Eqs. 1.1 and 1.2. At first glance, the benchmark autoregressive model performs adequately. All lagged inflation coefficients are significant at the 5\% level and add up to around 0.8-0.9 in both monthly and quarterly regressions indicating high level of persistence. Batini and Haldane (1999) also specify a central value of 0.8 for the UK inflation persistence parameter. A battery of diagnostic tests indicates that the residuals are serially uncorrelated. Ljung-Box and Breusch-Godfrey serial correlation tests are insignificant at all lags.

[Table 2 about here]

\subsection{Sensitivity analysis}

The results are examined for robustness with respect to a temporal sample division of particular interest for the British economy. We would expect inflation to exhibit a structural break around October 1992 when IT commenced. Therefore, 
Eqs. 1.1 and 1.2 are re-estimated for both sub-periods, before and after IT. The results indicate crucial changes in the time-series behaviour of inflation. In monthly regressions, columns 4-5 of Table 2, the estimated coefficient of 1-month lagged inflation $\left(\gamma_{1}\right)$ becomes insignificant during IT. On the other hand, the 12-month lag coefficient $\left(\gamma_{4}\right)$ increases substantially in magnitude and significance: from 0.098 and significant at the $10 \%$ level, it becomes 0.413 and significant at the $1 \%$ level. Similar patterns are revealed using quarterly data (Table 2, columns 8-9). Inflation persistence, as proxied by the coefficient of 1-quarter lagged inflation $\left(\gamma_{1}\right)$, turns out to be insignificant over the IT sub-period.

Parameter stability in Eqs. 1.1, 1.2 is formally tested with Chow breakpoint tests. With monthly data, the Chow F-statistic for breakpoint in October 1992 is significant at the $1 \%$ level, firmly rejecting the null of no-structural change in inflation dynamics. With quarterly data however, the Chow test fails to identify statistically significant structural change. Taking into account that the residual volatility of the estimated models is not equal over the two sub-samples but much higher during the pre-targeting period, we also calculate the Wald statistic for structural change that allows for unequal sub-sample variances. The null hypothesis of no structural change and independent samples is strongly rejected.

In general, temporal sample divisions and breakpoint tests suggest that the commonly employed benchmark autoregressive model is rather misspecified. In the following section we attempt a modification of the benchmark to avoid the instability arising from not modelling the effect of IT on inflation dynamics.

\subsection{Dummy variable model and the dynamics of inflation}

A multiplicative dummy variable is introduced in Eq. 1.1 via lags 1 and 12 and in Eq. 1.2 via the first lag, in order to allow for change in the slope of average inflation after targeting.

$$
\begin{aligned}
& \text { (M) } \pi_{t}=\gamma_{0}+\left(\gamma_{1}+\gamma_{5} D_{t}\right) \pi_{t-1}+\gamma_{2} \pi_{t-3}+\gamma_{3} \pi_{t-6}+\left(\gamma_{4}+\gamma_{6} D_{t}\right) \pi_{t-12}+e_{1 t} \\
& \text { (Q) } \pi_{t}=\gamma_{0}+\left(\gamma_{1}+\gamma_{3} D_{t}\right) \pi_{t-1}+\gamma_{2} \pi_{t-4}+e_{2 t}
\end{aligned}
$$

where $D_{t}$ is a dummy variable equal to zero during the pre-targeting period and one during $\mathrm{IT}^{3}$. Variants of the above equations, with lagged inflation augmented by indicators of policy regimes or economic events, are often employed in the inflation

\footnotetext{
${ }^{3}$ We experimented by allowing the IT dummy to interact with all lagged inflation variables but the results were similar to those from Eqs. 2.1 and 2.2 in terms of parameter significance and worse in diagnostics. We also allowed for intercept change but the dummy coefficient was insignificant and
} 
persistence literature (see e.g. Alogoskoufis, 1992). The results in Table 2 reveal an improvement in statistical performance associated with the dummy augmented models. The adjusted $\mathrm{R}^{2}$ increases while residual volatility declines ${ }^{4}$.

In monthly regressions, all inflation lags as well as the dummy coefficients $\gamma_{5}$ and $\gamma_{6}$ are significant at the $1 \%$ level -their negative sum $\left(\gamma_{5}+\gamma_{6}=-0.192\right)$ indicates that inflation persistence declined under IT. The Wald test-statistic, $X^{2}$ version, for the joint significance of $\gamma_{5}$ and $\gamma_{6}$ is equal to 15.59 , rejecting the null $\left(\gamma_{5}=\gamma_{6}=0\right)$ at the $1 \%$ level. In accordance with monthly results, estimates of the quarterly model 2.2 in Table 2 suggest that IT has eliminated inflation inertia. Using a Wald test, the hypothesis $\gamma_{1}+\gamma_{3}=0$ cannot be rejected at the usual levels of significance. Siklos (1999) agrees that inflation persistence has been significantly reduced in a number of explicit IT countries such as UK, New Zealand, and Canada among others. The dummy-augmented Eqs. 2.1, 2.2 offer two main advantages: first, improved fit and second, they allow verifying the negative effect from a decade of targeting on UK inflation persistence ${ }^{5}$.

\subsection{Time varying inflation volatility and pre-tests of the inflation-uncertainty link}

Before estimating the conditional variance of inflation, it is necessary to examine the residuals of the mean equation for time-varying volatility. The standard test is a Lagrange multiplier test developed by Engle (1982) and involves regressing the squared OLS residuals from the conditional mean against a constant and their lagged values:

$e_{t}^{2}=\delta_{0}+\sum_{i=1}^{q} \delta_{i} e_{t-i}^{2}+\theta_{t}$

where the null hypothesis of constant variance (homoskedasticity) implies that:

$\delta_{1}=\delta_{2}=\ldots=\delta_{q}=0$

Bollerslev (1986) shows that the LM test for a $q^{\text {th }}$ order ARCH is equivalent to a test for GARCH $(\mathrm{i}, \mathrm{j})$ where $i+j=q$. The results from the tests are reported in Table 3. There is overwhelming evidence that the residuals of the AR-dummy

the results are not presented to save space. In monthly regressions $D_{t}$ is zero before October 1992 and one onwards. In quarterly regressions $D_{t}$ is zero before 1992 Q4 and one onwards.

${ }^{4}$ In addition, CUSUM - CUSUM of squares tests for structural stability (available upon request) indicate substantial model fit improvement when $D_{t}$ is added in regressions Eqs. 1.1, 1.2.

${ }^{5}$ Some caution is required though. The dummy variable approach taken here allows the inflation dynamics to be constant before IT and to change only thereafter. Another strand of the literature presents time-varying estimates of inflation persistence using e.g. Kalman filter techniques (see for instance Bratsiotis et al, 2002). Ideally, the effect of IT on persistence should be examined in the context of such models. We thank a referee for raising this point. 
variable models 2.1 and 2.2 exhibit time-varying variance. The $F$ and $T R^{2}$ test statistics indicate that the null hypothesis of homoskedasticity is rejected. In addition, Ljung-Box statistics of the squared residuals $\left(Q^{2}\right)$ are all significant at the $1 \%$ level signifying the typical volatility clustering of an $\mathrm{ARCH}$ process. A key pattern emerging from Table 3 is that the IT period coincides with a significant reduction in the variability of inflation. While at the pre-targeting period there is strong evidence of time varying residual variance, the period after October 1992 is clearly more stable as none of the diagnistic statistics suggests ARCH effects.

[Table 3 about here]

A pre-test of the inflation-inflation uncertainty link can be performed by regressing the squared OLS residuals from the conditional mean (proxy for inflation uncertainty) on a constant and a variable representing the effect of past inflation. Three alternative lagged inflation variables were considered: the level of inflation (asymmetric measure), the absolute change in inflation, and squared inflation (symmetric measures) $^{6}$. The results are presented in Table 4. In full sample and pretargeting regressions uncertainty is significantly and positively related to symmetric and asymetric measures of past inflation. The relationship appears to break down during IT since none of the lagged inflation variables is different from zero at the usual levels of significance.

[Table 4 about here]

As Pagan (1984) argues, when working with generated regressors the simultaneous conditional mean and variance estimation implicit in $\mathrm{GARCH}$, is more efficient than the current two-step process. Hence, the last section examines the interaction between inflation, uncertainty and IT in the context of GARCH-related frameworks.

\subsection{GARCH models of inflation uncertainty}

A model that tests simultaneously the Friedman-Ball and Cukierman-Meltzer links is the GARCH-in-mean (GARCH-M) with the conditional variance augmented by lagged inflation (see for instance Fountas et al, 2000). We too allow for feedback effects between the conditional mean and the conditional variance by modifying mean equations 2.1 and 2.2 as follows:

\footnotetext{
${ }^{6}$ As Crawford and Kasumovich (1996) note, lower levels of inflation are expected to be associated with more stable and thus less uncertain inflation. The absolute change in inflation is employed to test whether inflation uncertainty is related to changes in inflation, as opposed to the level of inflation. Finally, squared inflation examines the possibility of a non-linear relationship between inflation and inflation uncertainty.
} 
where $h_{t}$ denotes the conditional variance of inflation ${ }^{7}$.

Coefficient $\delta$ represents the effect of inflation uncertainty on average inflation. An estimated positive and significant $\delta$ is interpreted as evidence in favour of the Cukierman-Meltzer argument. The augmented $\operatorname{GARCH}(\mathrm{p}, \mathrm{q})$ conditional variance models that we employ, utilise the following generic form:

$h_{t}=\varphi+\sum_{i=1}^{q} a_{i} e_{t-i}^{2}+\sum_{j=1}^{p} \beta_{j} h_{t-j}+\lambda^{\prime} z_{t}$

where $z_{t}=\left[\begin{array}{lll}z_{1 t} & \ldots & z_{n t}\end{array}\right]^{\prime}$, and $\lambda=\left[\begin{array}{lll}\lambda_{1} & \ldots & \lambda_{n}\end{array}\right]^{\prime}$ denote the vector of $n$-exogenous variance regressors and their coefficient vector respectively. The standard approach is to restrict $z_{t}$ to contain only past levels of inflation. In this case, estimated positive and significant $\lambda$-coefficients are consistent with the Friedman-Ball link. Brunner and Hess (1993) point out that, tests of the Friedman hypothesis (higher inflation leads to more variable inflation) are consistent only with $z_{t}$ including asymetric measures of past inflation ${ }^{8}$. Nevertheless, in order to examine whether inflation variability is affected by the direction and/or the magnitude of price level changes we employ both asymmetric, $z_{t}=\pi_{t-1}$, and symmetric, $z_{t}=\left|\pi_{t-1}\right|$, measures of lagged inflation.

[Table 5 about here]

As indicated in Table 5 by quasi-maximum likelihood ${ }^{9}$ estimates of the symmetric GARCH-M model formed by Eqs. 5.1, 5.2 and 6, there is a strong positive relationship between past inflation and the current conditional volatility of inflation. In most cases a $\operatorname{GARCH}(1,1)$ version of Eq. 6 is utilised. Ljung-Box statistics of the standarised and the squared standarised residuals are all insignificant implying proper model specification. In agreement with the Friedman-Ball link, the estimate of the 1-period lagged inflation coefficient, $\lambda$, is positive and statistically significant. Contrary to the Cukierman-Meltzer prediction, inflation uncertainty has no impact on average inflation as $\delta$ is insignificant in all cases. The finding of a

\footnotetext{
${ }^{7}$ The volatility measure used in the conditional mean Eqs. 5.1, 5.2 is standard deviation rather than variance. This approach to the in-mean modelling of inflation was introduced by Baillie et al (1996).

${ }^{8}$ On the other hand, asymmetric measures of lagged inflation imply that the monetary authority can reduce uncertainty by pursuing deflation Furthermore, improper negative estimates of the conditional variance may be obtained since sample monthly and quarterly inflation rates take both positive and negative values.

${ }^{9}$ Due to the departure of residuals from normality, as indicated by the Jarque-Berra test, we employ the quasi-maximum likelihood estimation which returns consistent estimates and compute standard errors using the method of Bollerslev and Wooldridge (1992).
} 
positive link between past inflation and current variability does not depend on the data frequency and on whether symmetric or assymetric inflation measures are in use. Figure I in Appendix scatter-plots estimates of the conditional variance from GARCH-M models versus the corresponding lagged inflation variable. The upward slopping fitted linear regression lines (top 2 diagrams) depict a positive relationship using both lagged and absolute lagged inflation. Kernel regression fitted lines (bottom 2 diagrams) reveal similar patterns.

The Threshold GARCH (TGARCH) model of Zakoian (1994) and Glosten et al (1993), as given by Eq. 7, allows for asymmetric news impact on inflation uncertainty:

$h_{t}=\varphi+\sum_{i=1}^{q} a_{i} e_{t-i}^{2}+\sum_{j=1}^{p} \beta_{j} h_{t-j}+\gamma w_{t-1} e_{t-1}^{2}+\lambda^{\prime} z_{t}$

where $w_{t}=1$ if $e_{t}<0$, and 0 otherwise. With quartely data, estimates of the TGARCH $(1,1)$ model in Table 5 suggest that the asymmetry parameter $\gamma$ is negative and statistically significant: 'good news' on inflation result in a smaller increase in inflation uncertainty than 'bad news'. Joyce (1995) presents collaborating evidence using quarterly UK data. Parameter $\gamma$ becomes insignificant in monthly results indicating that in the very short-run, both inflationary and deflationary shocks destabilise next period's inflation uncertainty. The positive relationship between the level of past inflation and current uncertainty appears robust to control for asymmetric effects as $\lambda>0$ and still highly significant.

IT should manifest itself in lower and more predictable inflation rates. Preeliminary evidence in Figure 1 and Tables 2-4 suggest that over the targeting years inflation volatility becomes smaller and its relationship with past inflation less pronounced. Panel evidence by Johnson (2002) using survey based measures of expected inflation indicates that while IT is succesuful in anchoring inflation expectations $^{10}$, there is no significant effect on the variance of expected inflation apart from the indirect effect of lower inflation. Table 6 presents estimates of the GARCH(1,1)-M and the TGARCH(1,1)-M conditional variance models augmented

\footnotetext{
${ }^{10}$ Two alternative approaches are employed in the literature to examine the effect of IT on expected inflation, a direct approach and an indirect approach. The indirect approach investigates whether the cost of disinflation (sacrifice ratio) declines after targeting. For instance, Clifton, Leon and Wong (2001) find that the adoption of IT reduces both trend inflation and the sacrifice ratio in a number of OECD countries. They also find that the improvement in the inflation-unemployment trade-off does not occur immediately after the announcement of IT but rather improves over time as the credibility of the new regime is established. The direct approach measures expected inflation using survey responses of professional forecasters (see among others Bernanke et al, 1999).
} 
by the IT dummy variable, $D_{t}$. Conditional mean parameters obtain values close to the estimates in Table 5 and are not presented to save space. The estimated dummycoefficient, $\lambda_{l}$, is negative and statistically significant at the $5 \%$ suggesting that inflation uncertainty has been lower during the IT period.

[Table 6 about here]

In order to examine whether lower uncertainty simply reflects lower average inflation as opposed to IT having an extra negative effect on uncertainty, we need to control for past inflation. Consequently, we report symmetric and asymmetric GARCH $(1,1)$ models using both 1-period lagged inflation and the IT dummy and as conditional variance regressors: $z_{t}=\left[\begin{array}{ll}D_{t} & \pi_{t-1}\end{array}\right]^{\prime}$. The quarterly results in Table 6 indicate that the impact of IT, as given by $\lambda_{l}$, remains negative and significant even after controlling for the standard relationship between average inflation and uncertainty. Some puzzle remains though, since the aforementioned finding is not verified for higher frequency uncertainty. In monthly results the dummy coefficient becomes indistinguishable from zero when past inflation is taken into account. It appears that the time-horizon employed matters, and that in the very short-run IT has no additional impact on inflation variability. Given however, that most of the inflation uncertainty costs involves long-run uncertainty and that inflation shocks cannot be reversed in the short-run, monetary authorities are more interested in how IT and average inflation affect a longer-run measure of uncertainty.

The Component GARCH (CGARCH) model by Engle and Lee (1993) decomposes inflation uncertainty into a short-run and a long-run component by permitting transitory deviations of the conditional volatility around a time-varying trend, $\varphi_{t}$.

$$
\begin{aligned}
& h_{t}=\varphi_{t}+a_{1}\left(e_{t-1}^{2}-\varphi_{t-1}\right)+\beta_{1}\left(h_{t-1}-\varphi_{t-1}\right) \\
& \varphi_{t}=\varphi+\rho \varphi_{t-1}+\mu\left(e_{t-1}^{2}-h_{t-1}\right)+\lambda^{\prime} z_{t}
\end{aligned}
$$

If $1>\rho>\left(\alpha_{1}+\beta_{1}\right)$, the transitory component in Eq. 8.1 will decay faster than the trend in Eq. 8.2, so that the trend will dominate the forecast of the conditional variance as the forecasting horizon increases ${ }^{11}$. Estimates of the CGARCH-M model in Table 6 support the view that IT reduces long-run inflation uncertainty as the dummy-coefficient in the permanent component, $\lambda_{l}$, is negative and significant. In an uncertain inflation environment, firms will be devoting part of their resources to

11 The Component GARCH model simplifies to the $\operatorname{GARCH}(1,1)$ model if $\rho=0$, or $\alpha_{1}+\beta_{1}=0$. See Engle and Lee (1993) for further discussion of stationarity and non-negativity restrictions. 
forecast and/or hedge against inflation which results to substantial distortions in the efficiency of resource allocation. The negative relationship between inflation targeting and uncertainty implies that successful targeters enjoy economic benefits far beyond the ones associated with lower level of nominal interest rates (as a result of lower average inflation).

Finding a positive link between past inflation and long-run uncertainty, $\lambda_{2}>0$, reinforces the argument for lower inflation. Ljung-Box statistics show no remaining serial correlation and $\mathrm{ARCH}$ effects in the standarised and the squared standarised residuals. The estimate of persistence in the permanent $\mathrm{CGARCH}$ component, $\rho$, is bellow unity ( $0.691,0.536$ with monthly, quarterly data respectively) implying that long-run mean reversion of inflation's conditional variance does not occur very slowly.

\section{Conclusions}

This papers looks at the relationship between average inflation - inflation uncertainty and at the impact of explicit targeting in the context of the UK economy. The significant economic costs of inflation uncertainty are well established in the literature. Higher uncertainty implies more frequent negotiations of nominal contracts, undermines the economic agents' task to distinguish between nominal and relative price changes, and may adversely affect real activity. The results from symmetric, asymmetric and component GARCH inflation models indicate a positive relationship between past inflation and uncertainty about future inflation, in line with the Friedman-Ball causal link. The policy implication for high inflation countries is to aim at low average inflation rates in order to reduce the negative consequences of uncertainty.

The key contribution of this paper is that the establishment of IT ever since October 1992 is explicitly modelled, allowing to examine its effect on inflation dynamics and uncertainty. The results show that in the post-targeting period UK inflation is substantially less persistent and less variable. Even after we control for the effect of lower average inflation throughout that period, we can still identify a direct negative impact from IT on long-run uncertainty, suggesting an independent role for formal targets. The monetary authorities of non-IT countries should acknowledge the long-run benefits associated with the adoption of explicit targeting. Further work should examine the inflation - uncertainty relationship with data from 
other IT countries and using alternative specifications for the conditional mean of inflation. 


\section{FIGURES}

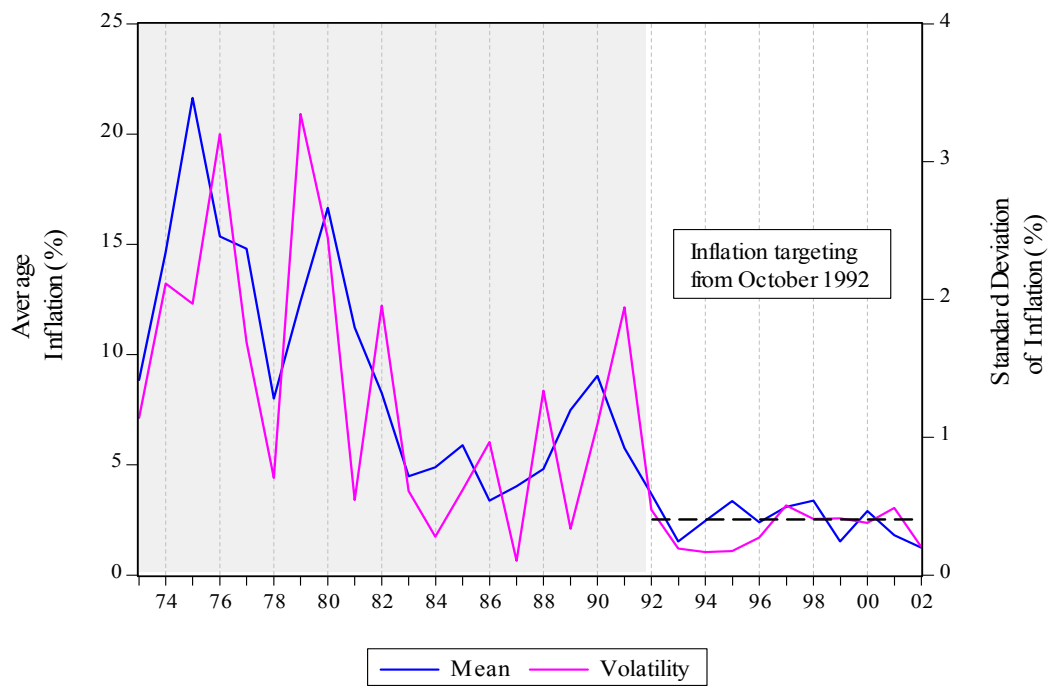

Figure 1: Annual inflation rate, United Kingdom, 1973-2002

\section{TABLES}

Table 1: Unit root Tests, UK CPI inflation rate, 1972-2002

\begin{tabular}{cccccc}
\hline \multicolumn{4}{c}{ Monthly } & \multicolumn{3}{c}{ Quarterly } \\
\hline$d$ & ADF & PP & $d$ & ADF & PP \\
UB: 4 & $-5.82 * * *$ & $-11.59 * * *$ & UB: 1 & $-4.39 * * *$ & $-6.21 * * *$ \\
LB: 24 & $-3.21 *$ & $-13.94 * * *$ & LB: 8 & $-3.33 *$ & $-6.52 * * *$ \\
R: 11 & $-3.58 * *$ & $-14.21 * * *$ & R: 7 & $-3.52 * *$ & $-6.49 * * *$ \\
SIC: 5 & $-4.31 * * *$ & $-12.99 * * *$ & SIC: 0 & $-6.31 * * *$ & $-6.31 * * *$ \\
\hline
\end{tabular}

Note: (a) An intercept and a deterministic trend are included in the Augmented Dickey Fuller (ADF) and Philips Perron (PP) models. Inclusion of the trend is needed to capture the reduction in average inflation that took place throughout the sample period. The reported $t$-statistics test the null hypothesis that inflation contains a unit root (b) In order to correct for serial correlation, ADF uses $d$ lagged differences of inflation. PP tests employ a non-parametric estimator of the variance-covariance matrix with $d$ truncation lags. (c) UB: upper bound of lagged difference terms; LB: lower bound of lagged difference terms; R: number of lagged difference terms chosen by the reduction criterion. In the ADF regressions we set an upper bound of lagged differences, equal to UB, and test down by sequentially removing the last lag until a significant (at 5\% level) lag is reached; SIC: order of augmentation for ADF that minimises the Schwartz information criterion starting from upper bound UB. (d) *, **,*** indicate rejection of the null-unit root hypothesis at 10,5,1\% level of significance respectively. 
Table 2: OLS robust estimates of inflation conditional mean equations 1.1 to 2.2

\begin{tabular}{|c|c|c|c|c|c|c|c|c|}
\hline & \multicolumn{4}{|c|}{ Monthly Regressions } & \multicolumn{4}{|c|}{ Quarterly Regressions } \\
\hline & \multicolumn{2}{|c|}{$02 / 73-11 / 02$} & $02 / 73-09 / 92$ & $10 / 92-11 / 02$ & \multicolumn{2}{|c|}{$02 / 73-03 / 02$} & $02 / 73-03 / 92$ & $04 / 92-03 / 02$ \\
\hline & \multicolumn{2}{|c|}{ Full Sample } & Pre-Target & After-Target & Full & nple & Pre-Target & After-Target \\
\hline & Equation 1.1 & Equation 2.1 & \multicolumn{2}{|c|}{ Equation 1.1} & Equation 1.2 & Equation 2.2 & \multicolumn{2}{|c|}{ Equation 1.2} \\
\hline Coetficients & & & & & & & & \\
\hline$\gamma_{0}$ & $0.051 *$ & $0.078 * * *$ & $0.108 *$ & 0.041 & $0.231 * *$ & $0.446 * * *$ & $0.458 * *$ & $0.453 * * *$ \\
\hline$\gamma_{1}$ & $0.339 * * *$ & $0.408 * * *$ & $0.398 * * *$ & 0.008 & $0.659 * * *$ & $0.644 * * *$ & $0.639 * * *$ & 0.133 \\
\hline$\gamma_{2}$ & $0.176 * * *$ & $0.145 * * *$ & $0.132 *$ & $0.197 * *$ & $0.196 * *$ & $0.151 *$ & 0.152 & 0.101 \\
\hline$\gamma_{3}$ & $0.235 * * *$ & $0.215 * * *$ & $0.218 * * *$ & $0.168 * *$ & - & $-0.541 * * *$ & - & - \\
\hline$\gamma_{4}$ & $0.151 * * *$ & $0.11 * * *$ & $0.098 *$ & $0.413 * * *$ & - & - & - & - \\
\hline$\gamma_{5}$ & - & $-0.445 * * *$ & - & - & - & - & - & - \\
\hline$\gamma_{6}$ & - & $0.253 * * *$ & - & - & - & - & - & - \\
\hline \multicolumn{9}{|l|}{ Diagnostic Statistics } \\
\hline Adjusted $\mathrm{R}^{2}$ & 0.49 & 0.52 & 0.41 & 0.33 & 0.62 & 0.64 & 0.50 & 0.02 \\
\hline Residual stand. dev. & 0.432 & 0.423 & 0.491 & 0.244 & 0.923 & 0.907 & 1.08 & 0.38 \\
\hline $\mathrm{Q}(1)$ & 0.129 & 0.007 & 0.045 & 1.596 & 1.508 & 1.096 & 0.852 & 0.094 \\
\hline $\mathrm{Q}(4)$ & 2.098 & 1.434 & 1.244 & 2.167 & 4.564 & 4.805 & 3.521 & 0.470 \\
\hline $\mathrm{Q}(12)$ & 3.272 & 9.045 & 7.631 & 4.199 & 13.445 & 13.014 & 9.856 & 10.081 \\
\hline $\mathrm{T}^{*} \mathrm{R}^{2}(4)$ & 7.03 & 3.50 & 2.59 & 4.76 & 8.15 & 5.55 & 4.82 & 6.68 \\
\hline $\mathrm{T}^{*} \mathrm{R}^{2}(12)$ & 16.34 & 10.61 & 9.67 & 11.66 & 14.80 & 13.41 & 9.73 & 11.66 \\
\hline \multicolumn{5}{|c|}{$\begin{array}{l}\text { Testing for break-point at 10/1992: Chow-break point- F-test : } 3.27 * * * \\
\text { Wald } \mathrm{X}^{2} \text {-test for structural change: } 30.48 * * *\end{array}$} & \multicolumn{4}{|c|}{$\begin{array}{l}\text { Testing for break-point at } 04 / 1992 \text { Chow-break point- F-test : } 4.26 \\
\text { Wald } \mathrm{X}^{2} \text {-test for structural change: } 12.76 * * *\end{array}$} \\
\hline
\end{tabular}

Note: (a) Q, TR ${ }^{2}$ denote the Ljung-Box, Breusch-Godfrey test statistics for serial correlation.

(b)*,**,*** indicate statistical significance at the $10,5,1 \%$ level respectively. 
Table 3: Testing for time-varying residual variance in the conditional mean

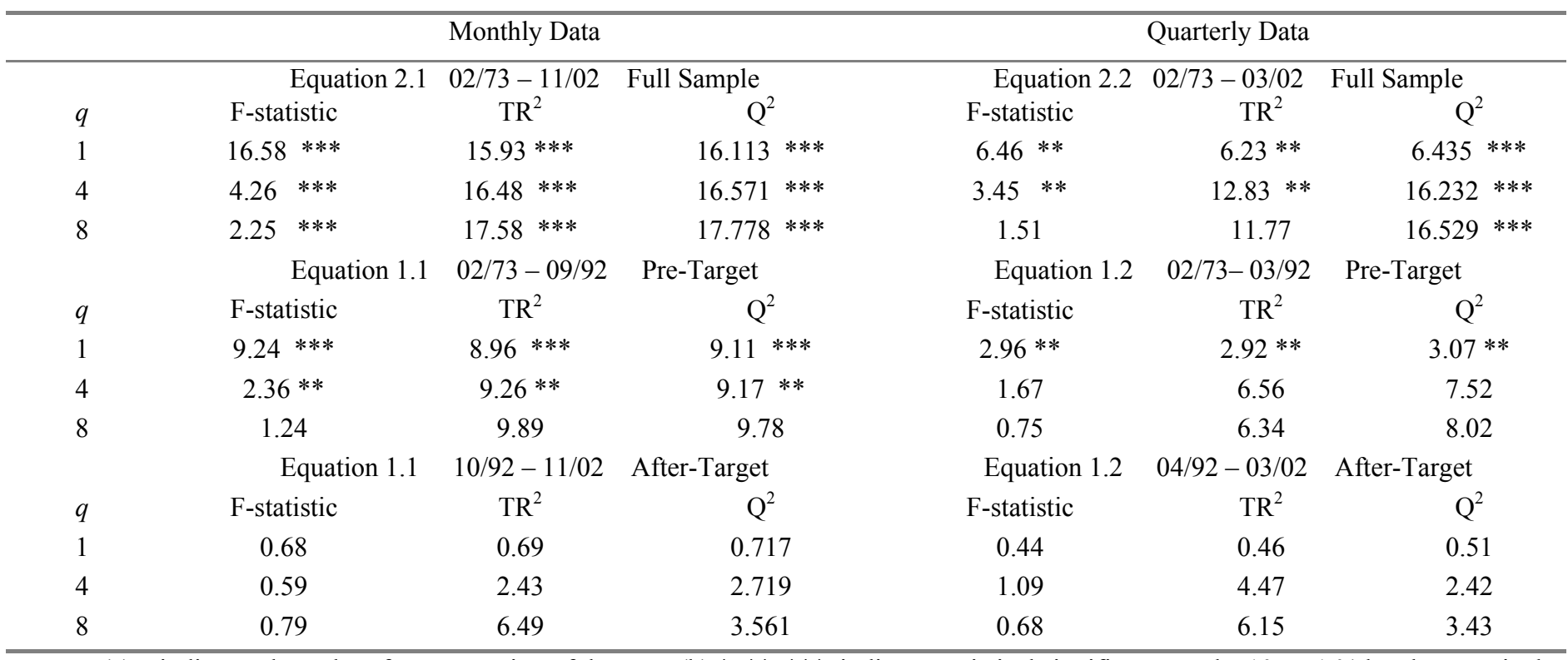

Note: (a) $q$ indicates the order of augmentation of the test. (b) *, **, *** indicate statistical significance at the $10,5,1 \%$ level respectively.

Table 4: Inflation uncertainty and lagged inflation variables

\begin{tabular}{|c|c|c|c|c|c|c|}
\hline \multirow{2}{*}{$\begin{array}{c}\text { Lagged Inflation } \\
\text { Variable }\end{array}$} & \multicolumn{3}{|c|}{ Monthly Regressions } & \multicolumn{3}{|c|}{ Quarterly Regressions } \\
\hline & $02 / 73-11 / 02$ & $02 / 73-09 / 92$ & $10 / 92-11 / 02$ & $02 / 73-03 / 02$ & $02 / 73-03 / 92$ & $04 / 92-03 / 02$ \\
\hline$\pi_{\mathrm{t}-1}$ & $0.392 * * *$ & $0.457 * * *$ & -0.033 & $0.518 * * *$ & $0.503 * * *$ & -0.052 \\
\hline$\left|\Delta \pi_{\mathrm{t}-1}\right|$ & $0.293 * * *$ & $0.349 * * *$ & -0.06 & $0.692 * * *$ & $0.598 * * *$ & -0.036 \\
\hline
\end{tabular}

Note: (a) The table presents the estimated coefficient of the lagged inflation variable obtained by regressing the squared OLS residuals from

Equations 1.1 to 2.2 on a constant and the lagged inflation variable. (b) *,**,*** indicate statistical significance at the $10,5,1 \%$ level respectively. 
Table 5: Symmetric and Threshold GARCH (p,q) -M models augmented by lagged inflation variables

\begin{tabular}{|c|c|c|c|c|c|c|}
\hline & \multicolumn{3}{|c|}{ Monthly Regressions: 02/73 - 11/02 } & \multicolumn{3}{|c|}{ Quarterly Regressions: 02/73 - 03/02 } \\
\hline & \multicolumn{2}{|c|}{$\begin{array}{l}\text { Symmetric } \\
\text { GARCH-M }\end{array}$} & $\begin{array}{c}\text { Threshold } \\
\text { GARCH-M }\end{array}$ & \multicolumn{2}{|c|}{$\begin{array}{l}\text { Symmetric } \\
\text { GARCH-M }\end{array}$} & $\begin{array}{c}\text { Threshold } \\
\text { GARCH-M }\end{array}$ \\
\hline $\begin{array}{c}\text { Conditional } \\
\text { Mean }\end{array}$ & \multicolumn{2}{|c|}{5.1} & 5.1 & \multicolumn{2}{|c|}{5.2} & 5.2 \\
\hline$\gamma_{0}$ & 0.086 & $0.125 * * *$ & 0.057 & $0.511 * * *$ & $0.451 * * *$ & 0.223 \\
\hline$\gamma_{1}$ & $0.519 * * *$ & $0.532 * * *$ & $0.513 * * *$ & $0.755 * * *$ & $0.585 * * *$ & $0.521 * * *$ \\
\hline$\gamma_{2}$ & $0.153 * * *$ & $0.143 * * *$ & $0.155 * * *$ & $0.147 * *$ & $0.099 *$ & $0.125 *$ \\
\hline$\gamma_{3}$ & $0.119 * *$ & $0.116 * *$ & $0.116 * * *$ & $-0.471 * * *$ & $-0.521 * * *$ & $-0.65 * * *$ \\
\hline$\gamma_{4}$ & $0.052 *$ & 0.036 & $0.055 *$ & - & & - \\
\hline$\gamma_{5}$ & $-0.479 * * *$ & $-0.574 * * *$ & $-0.538 * * *$ & - & & - \\
\hline$\gamma_{6}$ & $0.391 * * *$ & $0.392 * * *$ & $0.425 * * *$ & - & & - \\
\hline$\delta$ & -0.006 & -0.053 & 0.089 & -0.338 & 0.268 & -0.003 \\
\hline Conditional & $(p, q)=(1,1)$ & $(\mathrm{p}, \mathrm{q})=(0,1)$ & $(p, q)=(1,1)$ & $(p, q)=(1,1)$ & $(\mathrm{p}, \mathrm{q})=(1,1)$ & $(p, q)=(1,1)$ \\
\hline Variance & $\mathrm{z}_{\mathrm{t}}=\pi_{\mathrm{t}-1}$ & $\mathrm{z}_{\mathrm{t}}=\left|\pi_{\mathrm{t}-1}\right|$ & $\mathrm{Z}_{\mathrm{t}}=\pi_{\mathrm{t}-1}$ & $\mathrm{z}_{\mathrm{t}}=\pi_{\mathrm{t}-1}$ & $z_{t}=\left|\pi_{t-1}\right|$ & $\mathrm{z}_{\mathrm{t}}=\pi_{\mathrm{t}-1}$ \\
\hline$\varphi$ & 0.007 & 0.005 & 0.012 & -0.020 & -0.021 & $0.101 * *$ \\
\hline$\alpha_{1}$ & $0.247 *$ & $0.369 * *$ & 0.421 & 0.007 & 0.003 & $0.225 *$ \\
\hline$\beta_{1}$ & $0.410 * *$ & - & $0.426 * *$ & $0.474 * * *$ & $0.380 * *$ & $0.495 * * *$ \\
\hline$\lambda$ & $0.085 * *$ & $0.167 * * *$ & $0.064 *$ & $0.229 * * *$ & $0.252 * * *$ & $0.112 * *$ \\
\hline$\gamma$ & - & - & -0.277 & - & - & $-0.403 * * *$ \\
\hline Diagnostic & $\mathrm{LL}=-119.54$ & $\mathrm{LL}=-112.96$ & $\mathrm{LL}=-117.70$ & $\mathrm{LL}=-122.32$ & $\mathrm{LL}=-124.82$ & $\mathrm{LL}=-125.82$ \\
\hline \multirow[t]{5}{*}{ Statistics } & $\mathrm{Q}(1)=0.536$ & $\mathrm{Q}(1)=0.761$ & $\mathrm{Q}(1)=0.825$ & $\mathrm{Q}(1)=1.116$ & $\mathrm{Q}(1)=0.200$ & $\mathrm{Q}(1)=0.018$ \\
\hline & $\mathrm{Q}(4)=3.867$ & $\mathrm{Q}(4)=1.418$ & $\mathrm{Q}(4)=1.702$ & $\mathrm{Q}(4)=3.838$ & $\mathrm{Q}(4)=3.469$ & $\mathrm{Q}(4)=3.098$ \\
\hline & $\mathrm{Q}(12)=5.593$ & $\mathrm{Q}(12)=5.582$ & $\mathrm{Q}(12)=4.116$ & $\mathrm{Q}(12)=8.485$ & $Q(12)=14.671$ & $\mathrm{Q}(12)=9.801$ \\
\hline & $\mathrm{Q}^{2}(4)=3.466$ & $\mathrm{Q}^{2}(4)=4.098$ & $\mathrm{Q}^{2}(4)=3.974$ & $\mathrm{Q}^{2}(4)=2.372$ & $\mathrm{Q}^{2}(4)=1.614$ & $\mathrm{Q}^{2}(4)=1.672$ \\
\hline & $\operatorname{TR}^{2}(8)=12.32$ & $\mathrm{TR}^{2}(8)=12.24$ & $\mathrm{TR}^{2}(8)=12.85$ & $\mathrm{TR}^{2}(8)=3.39$ & $\mathrm{TR}^{2}(8)=2.35$ & $\mathrm{TR}^{2}(8)=1.74$ \\
\hline
\end{tabular}

Note: (a) $p, q$ represent the order of the GARCH, ARCH term respectively. (b) Diagnostic statistics are based upon the standardised residuals. LL denotes the maximised log-

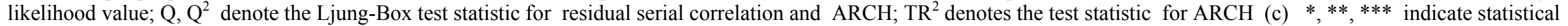
significance at the $10,5,1 \%$ level respectively. 
Table 6: Threshold and Component GARCH (p,q) -M models augmented by past inflation and targeting dummy.

\begin{tabular}{|c|c|c|c|c|c|c|}
\hline & \multicolumn{3}{|c|}{ Monthly Regressions: 02/73 - 11/02 } & \multicolumn{3}{|c|}{ Quarterly Regressions: 02/73-03/02 } \\
\hline & Symmetric & Symmetric & Component & Threshold & Threshold & Component \\
\hline & GARCH-M & GARCH-M & GARCH-M & GARCH-M & GARCH-M & GARCH-M \\
\hline Variance & $\mathrm{z}_{\mathrm{t}}=\mathrm{D}_{\mathrm{t}}$ & $\mathrm{z}_{\mathrm{t}}=\left[\begin{array}{ll}\mathrm{D}_{\mathrm{t}} & \pi_{\mathrm{t}-1}\end{array}\right]$ & $\mathrm{z}_{\mathrm{t}}=\left[\begin{array}{ll}\mathrm{D}_{\mathrm{t}} & \pi_{\mathrm{t}-1}\end{array}\right]$ & $\mathrm{z}_{\mathrm{t}}=\mathrm{D}_{\mathrm{t}}$ & $\mathrm{z}_{\mathrm{t}}=\left[\begin{array}{ll}\mathrm{D}_{\mathrm{t}} & \pi_{\mathrm{t}-1}\end{array}\right]$ & $\mathrm{Z}_{\mathrm{t}}=\left[\begin{array}{ll}\mathrm{D}_{\mathrm{t}} & \pi_{\mathrm{t}-1}\end{array}\right]$ \\
\hline$\alpha_{1}$ & $0.455 * *$ & $0.239 *$ & $0.423 *$ & $0.185 * * *$ & $0.126 * *$ & $0.395 *$ \\
\hline$\beta_{1}$ & $0.421 * *$ & $0.281 * * *$ & 0.010 & $0.747 * * *$ & $0.589 * * *$ & -0.087 \\
\hline$\lambda_{1}$ & $-0.031 * *$ & 0.004 & $-0.037 *$ & $-0.144 * * *$ & $-0.276 * *$ & $-0.215 *$ \\
\hline$\lambda_{2}$ & - & $0.115 * * *$ & $0.061 * * *$ & - & $0.135 *$ & $0.141 * *$ \\
\hline$\gamma$ & - & - & - & $-0.537 * * *$ & $-0.359 * * *$ & - \\
\hline$\rho$ & - & - & $0.691 * * *$ & - & - & $0.536 * * *$ \\
\hline \multirow[t]{4}{*}{ Statistics } & $\mathrm{Q}(4)=3.705$ & $\mathrm{Q}(4)=2.529$ & $\mathrm{Q}(4)=2.021$ & $\mathrm{Q}(4)=2.974$ & $\mathrm{Q}(4)=2.521$ & $\mathrm{Q}(4)=3.771$ \\
\hline & $\mathrm{Q}(12)=10.08$ & $\mathrm{Q}(12)=6.727$ & $\mathrm{Q}(12)=8.803$ & $\mathrm{Q}(12)=9.546$ & $\mathrm{Q}(12)=8.791$ & $\mathrm{Q}(12)=10.204$ \\
\hline & $\mathrm{Q}^{2}(4)=3.705$ & $Q^{2}(4)=3.879$ & $Q^{2}(4)=5.607$ & $\mathrm{Q}^{2}(4)=2.152$ & $Q^{2}(4)=1.722$ & $\mathrm{Q}^{2}(4)=2.398$ \\
\hline & $\mathrm{TR}^{2}(8)=8.95$ & $\mathrm{TR}^{2}(8)=11.57$ & $\mathrm{TR}^{2}(8)=10.23$ & $\mathrm{TR}^{2}(8)=2.59$ & $\mathrm{TR}^{2}(8)=2.06$ & $\mathrm{TR}^{2}(8)=2.321$ \\
\hline
\end{tabular}

Note: (a) Parameters from the conditional mean Eqs. 5.1 (monthly), 5.2 (quarterly) are not reported. (b) $p$, $q$ represent the order of the GARCH, ARCH term respectively. (b) Diagnostic statistics are based upon the standardised residuals. LL denotes the maximised log-likelihood value; $\mathrm{Q}, \mathrm{Q}^{2}$ denote the Ljung-Box test statistic for residual serial correlation and $\mathrm{ARCH} ; \mathrm{TR}^{2}$ denotes the test statisticfor $\mathrm{ARCH}(\mathrm{c}) * * * *, * * *$ indicate statistical significance at the 10, 5, $1 \%$ level respectively. 


\section{APPENDIX}
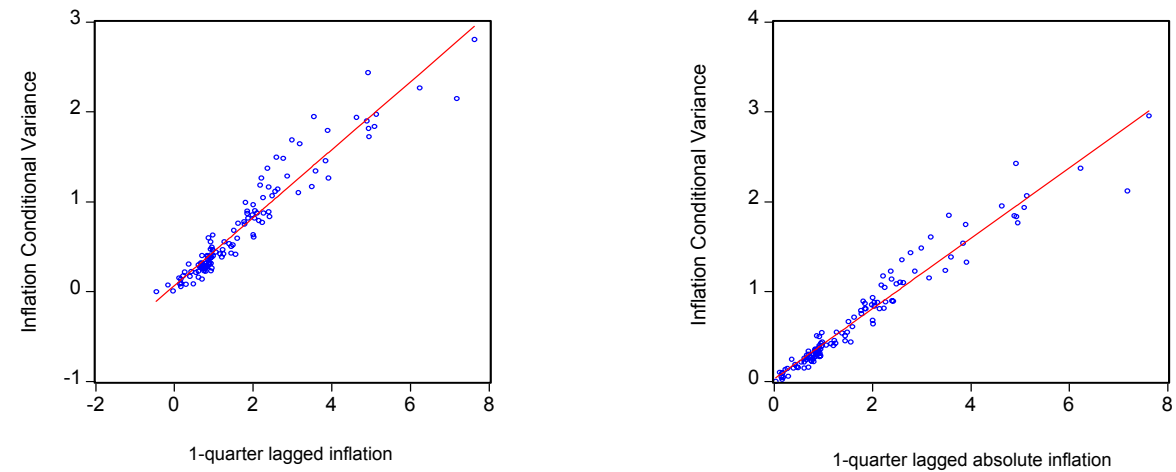

Kernel Fit (Epanechnikov, $h=1.2129$ )
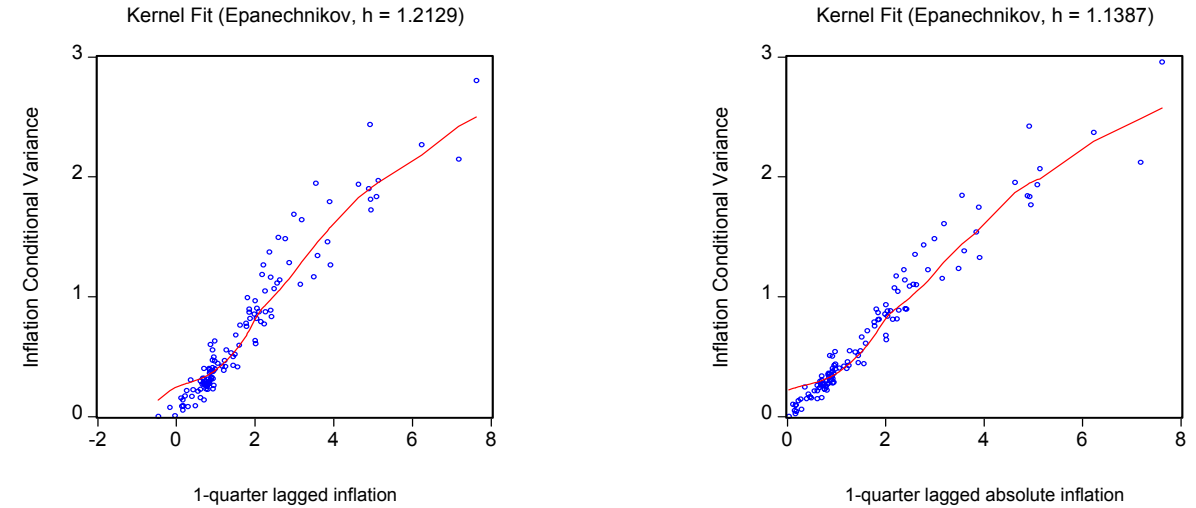

Figure I: Scatter plots and linear - kernel fit regressions lines of symmetric quarterly GARCH-M conditional variance versus past inflation

Note: Local polynomial kernel regressions fit $\mathrm{Y}$, at each value $\mathrm{x}$, by choosing the parameters $\beta$ to minimise the weighted sum-of-squared residuals: $m(x)=\sum_{i=1}{ }^{N}\left[\left(Y_{i}-\beta_{0}-\beta_{1}\left(x-X_{i}\right)-\ldots-\beta_{k}\left(x-X_{i}\right)^{k}\right]^{2} K\left(x-X_{i}\right) / h\right.$ where $\mathrm{N}$ is the number of observations, $\mathrm{h}$ is the smoothing parameter (bandwidth) and $\mathrm{K}$ is a Kernel function that integrates to one. In specifying the order of the polynomial to be fitted at each data point, the local linear option, that sets $\mathrm{k}=1$ at each $\mathrm{x}$, was selected. The Kernel weighting function employed is the Epanechnicov function.

\section{ACKNOWLEDGMENTS}

I would like to thank two anonymous referees of this journal, Christos Ioannidis, Andros Gregoriou, Alberto Montagnoli, Nick Tsitsianis and participants at a conference in Brunel University for their most valuable comments and suggestions on an earlier version of this paper. Any remaining errors are sole responsibility of the author. 


\section{REFERENCES}

Alogoskoufis, G., 1992. Monetary accommodation, exchange rate regimes, and inflation persistence. Economic Journal 102, 461-480.

Ball, L., 1992. Why does higher inflation raise inflation uncertainty? Journal of Monetary Economics 29, 371-378.

Ball, L., and Cecchetti S., 1990. Inflation uncertainty at short and long horizons. Brooking Papers on Economic Activity 1, 215-245.

Baillie, R., Chung, C., and Tieslau, M., 1996. Analysing inflation by the fractionally integrated ARFIMAGARCH Equation. Journal of Applied Econometrics 11, 23-40.

Batini, N., and Haldane, A., 1999. Forward looking rules for monetary policy. Bank of England Working Paper 91.

Bernanke, B., Laubach T., Mishkin F., and Posen A., 1999. Inflation targeting: Lessons from the international experience. Princeton University Press, Princeton, NJ.

Bollerslev, T., 1986. Generalised autoregressive conditional heteroskedasticity. Journal of Econometrics 31, 307-327.

Bollerslev, T., and Wooldridge, J., 1992. Quasi-maximum likelihood estimation and inference in dynamic Equations with time varying covariances. Econometric Reviews 11, 143-172.

Bratsiotis, G., Madsen, J., and Martin, C., 2002. Inflation targeting and inflation persistence. Brunel University Working Paper No. 02-12.

Brunner, A., and Hess, G., 1993. Are higher levels of inflation less predictable? A state-dependent conditional heteroskedasticity approach. Journal of Business and Econ. Statistics 11, 187-197.

Cecchetti S., and Ehrmann M., 2000. Does inflation targeting increase output volatility? An international comparison of policymakers' preferences and outcomes. Central Bank of Chile Working Paper 69.

Clifton, E., Leon, H., and Wong, C.H., 2001. Inflation targeting and the unemployment-inflation trade-off. IMF Working Paper 01/166.

Crawford, A., and Kasumovich, M., 1996. Does inflation uncertainty vary with the level of inflation? Bank of Canada Working Paper 96-09.

Cukierman, A., 1992. Central Bank strategy: credibility and independence. MIT Press, Cambridge.

Cukierman, A., and Meltzer, A., 1986. A theory of ambiguity, credibility, and inflation under discretion and asymmetric information. Econometrica 54, 1099-1128.

Engle, R., 1982. Autoregressive conditional heteroskedasticity with estimates of the variance of UK inflation. Econometrica 50, 987-1007.

Engle, R., and Lee, G., 1993. A permanent and transitory component model of stock return volatility. University of San Diego Discussion Paper 92-44R.

Evans, M., 1991. Discovering the link between inflation rates and inflation uncertainty. Journal of Money Credit and Banking 23, 169-184.

Friedman, M., 1977. Nobel lecture: inflation and unemployment. Journal of Political Economy 85, 451-472.

Fischer, S., 1981. Towards an understanding of the costs of inflation: II. Carnegie-Rochester Conference Series on Public Policy 15, 5-41.

Fountas, S., Karanasos M., and Karanasou M., 2000. A GARCH model of inflation and inflation uncertainty with simultaneous feedback. University of York Discussion Paper 2000/24.

Glosten L., Jagannathan, R., and Runkle, D., 1993. On the relation between the expected value and the volatility of the normal excess return on stocks. Journal of Finance 48, 1779-1801.

Grier, K., and Perry, M., 1998. On inflation and inflation uncertainty in the G7 countries. Journal of International Money and Finance 17, 671-689.

Johnson, D., 2002. The effect of inflation targeting on the behavior of expected inflation: evidence from an 11 country panel. Journal of Monetary Economics 49, 1521-1538.

Joyce, M., 1995. Modelling UK inflation uncertainty: the impact of news and the relationship with inflation. Bank of England Working Paper 30.

Okun, A., 1971. The mirage of steady inflation. Brooking Papers on Economic Activity 2, 485-498.

Pagan, A., 1984. Econometric issues in the analysis of regressions with generated regressors. International Economic Review 25, 221-247.

Siklos, P., 1999. Inflation-target design: Changing inflation performance and persistence in industrial countries. Federal Reserve Bank of Saint Louis Review, March-April, 47-58.

Zakoian, J., 1994. Threshold Heteroskedastic Models. Journal of Economic Dynamics and Control 18, 931944. 